doi.org/ 10.51891/rease.v8i1.3837

\title{
ENSINO HÍBRIDO: UMA NOVA PERSPECTIVA PARA O ENSINO
}

\author{
Eliane de Jesus Araujo ${ }^{1}$ \\ Solange Amorim Ozório Melo
}

RESUMO: Este artigo é uma pesquisa bibliográfica e tem por objetivo analisar o ensino mediado por tecnologia durante e pós a pandemia da COVID-ı, e investigar os modelos de ensino híbrido apresentado como um dos caminhos possíveis para a melhoria da educação pública. Faz uma breve explanação sobre o ensino híbrido, observando a realidade da instituição de ensino, apontando a importância dos atores educacionais nessa nova metodologia de ensino. Aborda a ressignificação das práticas pedagógicas, a reformulação do planejamento educacional, o diagnóstico assertivo e a parceria dos profissionais que integram a comunidade escolar.

Palavras-chave: Ensino híbrido. Tecnologia. organização curricular.

ABSTRACT: This article is bibliographical research that aims to analyze technology-mediated teaching during and after the COVID-19 pandemic, and to investigate the hybrid teaching models presented as one of the possible ways to improve public education. It makes a brief explanation about hybrid teaching, observing the reality of the educational institution, pointing out the importance of educational actors in this new teaching methodology. It addresses the resignification of pedagogical practices, the reformulation of educational planning, the assertive diagnosis and the partnership of professionals who make up the school community.

Keywords: Blended learning. Technology. curriculum organization.

\section{INTRODUÇÃO}

Desde o mês de março do ano 2020, os recursos digitais vêm facilitando a comunicação e o acesso à informação na educação, pois as salas de aulas físicas passaram a ser telas: dos celulares, notebooks, TVs, dentre outros. A aula devido a esses facilitadores

\footnotetext{
${ }^{\mathrm{I}}$ Graduação em Pedagogia com habilitação em docência de $\mathrm{I}^{\mathrm{a}}$ à $4^{\underline{\underline{a}}}$ série e Gestão Escolar no Ensino Fundamental e Médio pela Universidade Estadual de Goiás (2005), licenciada também em Matemática pela Faculdade Albert Einstein, especialista em Orientação Educacional e Ensino Especial, Psicopedagogia Clínica e Institucional. Sou professora concursada no município de Novo Gama - GO desde 2002, atuando em regência da Educação Infantil ao ensino fundamental II, modalidade de EJA e ensino médio. Professora Tutora do Curso de Pedagogia ofertado pela Universidade Estadual de Goiás (Programa UEG em Rede) uma parceria do município de Novo Gama - GO e UEG, atuei ainda em várias funções com experiências muito importantes nos setores da SME de Novo Gama como: Diretora Pedagógica, Supervisão Pedagógica da SME, Coordenadora de Formação Continuada atuando em formações e tutorias dos variados cursos para os servidores que trabalham na educação do município. Formadora de Professores, Formação de conselheiros escolares e auxílio nas constituições dos Conselhos Escolares e demais comissões fiscalizadoras dos Planos: Municipal de Educação (2015 á 2025) e Ações Articuladas do município de Novo Gama - GO.

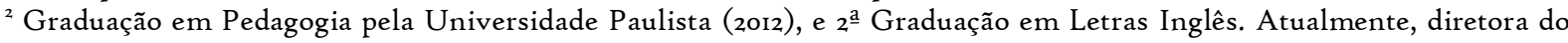
Centro Municipal de Atendimento Educacional Especializado - CMAEESP/ Secretaria Municipal de Educação, professora efetiva da PREFEITURA MUNICIPAL DE NOVO GAMA - GO, desde 2002. Tem experiência na área de Educação, e em Educação Especial. Possui Pós-graduação em Coordenação Pedagógica (UnB); em Gestão e Orientação Educação; em Psicopedagogia Clinica e Institucional; Pós em Neuropsicopedagogia e Educação Especial, Concluindo Pós Graduação em Docência Superior. Coordena os trabalhos dos Professores de AEE, das Escolas Públicas Municipais de Novo Gama Goiás. Atualmente é conselheira do Conselho Municipal de Educação de Novo Gama Goiás
} 
tecnológicos atravessou os muros da escola e passou a ocorrer em qualquer lugar que tivesse uma conexão com a internet. Isso por algum tempo foi muito assustador, as aulas não eram mais presenciais, do dia para a noite tiveram que ser revistas, as metodologias e didáticas de antes não serviam mais, várias técnicas tiveram que ser aperfeiçoadas e/ou até modificadas para que pelo menos a interação ocorresse entre professor e aluno.

$\mathrm{Na}$ tentativa de romper barreiras entre o docente e o discente, o professor que em muitas vezes foi visto como um transferidor de conhecimento precisou rever a atuação nesse período, passando a ser um mediador do processo educativo. É certo que, o professor durante a formação inicial não é preparado adequadamente, para agir em meio a tantas diversidades, e nem a escola possui estrutura para atender as necessidades pontuais dos professores e dos estudantes que as vezes se mostram desestimulados. Há anos a escola continuava a mesma. Assim, no ensino remoto o professor ficou exposto. E agir como repassador de conteúdos poderia descaracterizar a importância do profissional professor. Por certo, também foi visualizado por esse, que os conteúdos e informações são acessíveis a todo mundo com auxílio da tecnologia. Porém, os conhecimentos a serem adquiridos com a transformação da informação feita pelo docente é o que diferenciam do modo de só receber. Daí, percebe-se o quanto o professor é importantíssimo para manter o engajamento dos estudantes e mediar as informações de modo a promover com a ajuda dos recursos tecnológicos conhecimentos significativos.

Após quase dois anos no ensino remoto, o ensino presencial está retomando aos poucos e quem ainda não retornou, está se planejando para esse momento. Em alguns Estados e Municípios a rede pública está implementando o ensino híbrido, que é um modelo de ensino que vem sendo discutido há vários anos, mas que ganhou maior notoriedade nesse período de pandemia. Porém, percebe-se que ao mesmo tempo que já tinham discussões a respeito, esse tipo de ensino é novo para muitos professores, principalmente das escolas públicas. Então, como trazer para a realidade, para a sala de aula esse tipo de ensino? E quais as funções dos atores sociais?

De acordo com Freire (1996, p. 50), ele precisa ser "aventureiro, responsável, predisposto à mudança e à aceitação do diferente". E mesmo tendo algum tipo de limitação com os meios tecnológicos precisa buscar artifícios para melhorar o aprendizado dos seus alunos. Nesse contexto é essencial que os envolvidos na implementação do ensino híbrido adquiram empoderamento acerca da temática, para amparar todos os atores da escola, 
principalmente o professor que é, quem vai colocá-lo em prática, assim como o estudante que deverá se adequar a esse fim. Para que ambos possam sentir-se apoiados nos processos de ensinar e aprender nesse novo caminho, em prol do desenvolvimento da aprendizagem, é preciso conhecer o ensino híbrido.

\section{CARACTERIZAÇÃO DO ENSINO HÍBRIDO}

A primeira forma de trazer para a realidade o ensino híbrido é conhecer. Alguns autores trazem conceitos em relação ao tema: de acordo com Horn e Staker (2015. p. 34), o "Ensino híbrido é qualquer programa educacional formal no qual um estudante aprende, pelo menos em parte, por meio do ensino on-line, com algum elemento de controle dos estudantes sobre o tempo, o lugar, o caminho e/ou ritmo". Ou seja, ensino misto e/ou misturado (presencial com on-line).

Para Peres e Pimenta (20II), podem ser encontrados os termos para educação híbrida, como: b-learning, blended learning, educação bimodal, aprendizagem combinada, dual, semipresencial, semivirtual, bimodal e ensino híbrido, todos esses termos são sinônimos para descrever o ensino semipresencial, que segundo Peres e Pimenta (2oIr, p. 15), pretende "valorizar o melhor do presencial e do online". Todos esses ressaltam a combinação do ensino presencial com o on-line.

Já para Moran in Bachic, Tanzi Neto e Trevisani. (2015, p.27), "a educação sempre foi misturada, híbrida, combinou vários espaços, tempos, atividades, metodologias, públicos. Esse processo, agora, com a mobilidade e a conectividade, é muito mais perceptível, amplo e profundo: é um ecossistema mais aberto e criativo". Ele ainda diz que: Híbrido é um conceito rico, apropriado e complicado. Tudo pode ser misturado, combinado, e podemos, com os mesmos ingredientes, preparar diversos "pratos", com sabores diferentes.

Diante da fala de Moran, percebe-se a complexidade e ao mesmo tempo a ampliação de oportunidades que o termo híbrido, traz para a inovação nas práticas pedagógicas e principalmente para um ensino focado no desenvolvimento de aprendizagens. Ele ainda reafirma que "O ensino é híbrido porque não se reduz ao que planejamos institucional e intencionalmente”. A partir dessa frase, observamos o quanto ela se afirmou nesse período de pandemia em que a educação, escolas, gestores, professores, estudantes, famílias tinham seus planos para serem desenvolvidos ao longo do ano de 2020 e daí tiveram que rever, 
modificar, mudar, pois, foram pegos de surpresa por algo que desconheciam, e assim, para não serem atracados pela incerteza, adaptações foram feitas, aprendizagens foram ressignificadas. Novos conhecimentos e informações precisaram ser apropriadas para adequar-se a realidade do momento. Realidade essa, que fez inúmeras pessoas perceberem o quanto realmente são híbridas. Moran in Bachic, Tanzi Neto e Trevisani. (2015, p.28) diz que: "Muitos gestores, docentes e alunos são "híbridos", no sentido de contraditórios, pela formação desbalanceada (mais competências cognitivas que socioemocionais) e pelas dificuldades em saber conviver e aprender juntos".

Diante disso, entende-se o quanto a educação deve ser adequada para atender as reais necessidades de cada estudante, uma vez que sabemos o quanto o processo de ensino e aprendizagem ainda é desigual e não contempla a todos no sentido equitativo. Ou seja, o que o professor ensina nem todos compreendem, não pela frase que tanto ouvimos "uns são mais lentos para aprender" mais sim pelas desigualdades nesses processos que permeiam o desenvolvimento da aprendizagem, onde o que é ofertado para um, não quer dizer que seja o que o outro precisa. Daí, a necessidade de tanto professor, quanto gestores, estudantes, familiares e demais atores educacionais entenderem o ensino híbrido, como desenvolver, como planejar de acordo com a realidade presente. Moran enfatiza que:

São muitas as questões que impactam o ensino híbrido, o qual não se reduz a metodologias ativas, ao mix de presencial e on-line, de sala de aula e outros espaços, mas que mostra que, por um lado, ensinar e aprender nunca foi tão fascinante, pelas inúmeras oportunidades oferecidas, e, por outro, tão frustrante, pelas dificuldades em conseguir que todos desenvolvam seu potencial e se mobilizem de verdade para evoluir sempre mais. (MORAN in BACHIC, TANZI NETO e TREVISANI. 2015, p.29).

É pertinente, lembrar que o simples uso de um recurso tecnológico sem planejamento não quer dizer ensino híbrido e muito menos, pode gerar aprendizagem. Assim, cabe a escola juntamente com seus atores, antes da adoção de metodologia, fazer um diagnóstico do que tem disponível para adequar-se ao ensino híbrido, optando por qual combinação e/ou modelo será mais viável a realidade específica.

\section{ENSINO HÍBRIDO E MODELOS}

Para uma adequação correta do ensino híbrido é preciso analisar cada modelo e escolher a que melhor se encaixa na realidade de cada instituição de ensino. Sendo assim, é preciso conhecer esses modelos. De acordo com novais (2017): 
Modelo de Rotação: como o próprio nome sugere, os alunos revezam as atividades realizadas de acordo com um horário fixo ou não, sob orientação do professor. As atividades podem seguir para discussões com ou sem a presença do professor. Rotação por estações: organizados por grupo, os alunos realizam sua tarefa podendo ser escrita e desenvolvida on-line. Laboratório Rotacional: começa com a sala de aula tradicional, em seguida adiciona uma rotação para os computadores e/ ou laboratórios de ensino. Sala de aula invertida: o conteúdo teórico é estudado antecipadamente, no formato on-line, enquanto no espaço da sala de aula ocorrem as discussões.

Rotação Individual: cada aluno tem uma lista das propostas que deve contemplar em sua rotina para cumprir os temas a serem estudados. Modelo Flex: os estudantes de forma personalizada aprendem usufruindo as diferentes modalidades. Modelo a la carte: pode ser feito na escola física ou fora da aula. Isso difere do ensino on-line de tempo integral porque não é uma experiência de toda a escola. Modelo Virtual Enriquecido: é um curso ou uma disciplina em que os estudantes têm sessões de aprendizagem obrigatoriamente presencial na presença do professor responsável pela disciplina (NOVAIS, 2017, p.40-44).

Após essa conceituação de cada modelo é preciso que os atores de cada instituição de ensino analisem os mesmos, observando sempre o que há disponível para atender a escolha que irá adotar. Pois, o ensino híbrido não se iguala ao simples fato de utilizar um recurso tecnológico, ou levar os estudantes para um laboratório de informática hiper equipado. O que caracteriza o ensino híbrido é garantir que o estudante aprenda também com a utilização do on-line. Horn e Staker (2015, p.34-35) apontam três características básicas do ensino híbrido: A primeira é que o estudante aprenda, pelo menos, em parte, no ambiente virtual. A segunda, é que a aprendizagem ocorra em local físico distinto do lar. E a terceira, que as aprendizagens no ambiente on-line e físico estejam integradas.

Vale salientar que a intervenção pedagógica somente no ambiente on-line sem uma complementação no ambiente presencial ou vice-versa de nada valerá. É preciso, reconhecer que ambos são interdependentes e colaborativos.

\section{OS ATORES EDUCACIONAIS}

Ao iniciar o ensino remoto em março de dois mil e vinte, esperava-se que tanto os professores como os estudantes pudessem estar prontos para lidar com a tecnologia, pois ambos, participavam com frequência de redes sociais, plataforma WhatsApp, dentre outras. No entanto, isso não ocorreu. O profissional quando termina o curso superior e vai exercer a função de professor, costuma-se esperar que ele esteja preparado para a diversidade do contexto escolar o máximo possível. No entanto, constatou-se que ele não estava preparado para mudanças tão intensas do ensino remoto e nem tão pouco para 
mediar aulas com recursos tecnológicos. Poucos professores a princípio estavam preparados e sabiam utilizar a tecnologia no ensino, e a estes, ainda faltava a preparação para o contexto do ensino remoto. Então para atender a nova vertente e necessidades pontuais os professores procuraram se atualizar e adquirir conhecimentos que o ajudassem nessa versão da escola, através de pesquisa, estudo, suporte, orientações, se apropriando de formas possíveis, adaptadas ao ensino mediado por tecnologias.

Tanto para professores como para os estudantes, o uso das tecnologias digitais ainda é complexo em vários sentidos. Mesmo com quase dois anos de pandemia e com aulas mediadas por tecnologias, há professores e estudantes que não adquiriram experiências na utilização de recursos tecnológicos. Certos estudantes não tiveram acesso à internet e continuam sem, devido aos fatores econômicos. Mas, mesmo assim nessa conjuntura atual de retomada do ensino presencial e contando com uma adaptação desse retorno, para atender as reais necessidades de todos os estudantes é preciso que os atores se familiarizem com esses conhecimentos para o desenvolvimento dos processos de ensinar e aprender, aprender a aprender, ensinar aprendendo e assim por diante.

Os procedimentos de ensinar e aprender não são comuns e podem não ser alcançados apenas com o uso da tecnologia. Estudantes têm: ritmos, tempos e processos de aprendizagens distintos. Freire (2008, p.23) nos diz: "Não há docência sem discência, as duas se explicam e seus sujeitos, apesar das diferenças que os conotam, não se reduzem à condição de objeto, um do outro". Uma precisa da outra para existir, ou seja, são inseparáveis.

Assim, a organização curricular é tão importante quanto o processo de formação dos professores para o processo de ensino e aprendizagem. Por isso, a participação na construção e o aprimoramento da proposta pedagógica deve ocorrer com: pais, professores, coordenadores pedagógicos, gestores, técnicos das secretarias e estudantes. Todos precisam entender como irá funcionar, como será estabelecido a nova rotina.

Além dos desafios de aprender a usar a tecnologia, há um importante desafio que é do professor aprender a ser um mediador do conhecimento. Que passa do papel de despejar conteúdos, conceitos e saberes, para o que estimula, instiga e provoca o estudante a sair da zona de conforto para transformar informações em conhecimentos significativos e com sentido. 
Um dos problemas ocorrido na fase inicial do ensino remoto, foi que por não saber o que fazer, e diante da necessidade de adaptar a forma de ensinar por recursos tecnológicos, alguns professores somente entregaram as demandas para os estudantes realizarem, e com isso muitos equívocos foram ocorrendo. Pois, os estudantes estavam acostumados com o professor para explanar sobre os assuntos $e$ isso não estava funcionando naquele momento devido os recursos disponíveis para o professor e/ou para o estudante. Os estudantes ficavam perdidos e não sabiam o que fazer com algo que estava posto, com comandos que não alcançavam a compreensão para os mesmos. Para que essa mediação de fato ocorresse foi preciso que ambos compreendessem. Nesse sentido Morin, faz uma reflexão bem pertinente:

O problema da compreensão tornou-se crucial para os humanos. E, por este
motivo, deve ser uma das finalidades da educação do futuro. Lembremo-nos de
que nenhuma técnica de comunicação, do telefone à Internet, traz por si mesma a
compreensão. A compreensão não pode ser quantificada. Educar para
compreender a matemática ou uma disciplina determinada é uma coisa; educar
para a compreensão humana é outra. Nela encontra-se a missão propriamente
espiritual da educação: ensinar a compreensão entre as pessoas como condição e
garantia da solidariedade intelectual e moral da humanidade. (20or, p. 9o)

A educação do futuro precisa ter como um dos objetivos de acordo com Morin, "educar para a compreensão humana. E sobre a compreensão tecnológica, Brito (2006, p.16) diz que: "é necessário que o professor entenda a tecnologia como um instrumento de intervenção na construção da sociedade democrática, contrapondo-se a qualquer tendência que a direcione ao tecnicismo, a coisificação do saber e do ser humano”. O desafio do professor e da escola é estruturar caminhos para dar continuidade ao processo de ensino e aprendizagem dos alunos, atualizando e readequando conhecimentos metodológicos, utilizando tecnologias no cotidiano escolar, entendendo como irá utilizar no ensino híbrido na prática e de forma compreensiva.

É preciso entender o ensino híbrido primeiro na teoria e a partir desse entendimento, trazer para realidade da sua escola, da sua sala de aula, ou seja, como ele é traduzido no planejamento de uma aula. Saber como planejar para obter desenvolvimento de competências e habilidades dos estudantes que estão inseridos nesse processo.

A BNCC $^{3}$ destaca o conceito de competência como "a mobilização de conhecimentos (conceitos e procedimentos), habilidades (práticas, cognitivas e socioemocionais), atitudes e valores para resolver demandas complexas da vida cotidiana, do pleno exercício da cidadania e do mundo do trabalho”. E que a adoção/implantação do ensino híbrido significa um trabalho com o estudante no centro das aprendizagens, onde dependendo de como é envolvido é capaz de aprender sozinho, com professor e com seus

\footnotetext{
${ }^{3}$ Base Nacional Comum Curricular.
} 
pares, sendo essas aprendizagens interligadas ou interdisciplinares e com ensino por competências.

Vale ressaltar que no ensino por competências tanto o professor quanto o estudante precisam desenvolver habilidades para o saber fazer, pois não tem como ensinar sem aprender a ensinar, assim como não tem habilidade sem a prática.

Não é porque o ensino híbrido está sendo um caminho para adequar mais uma vez a educação no período pandêmico, que os saberes obtidos e as práticas construídas antes desse e no decorrer serão minimizados. Freire (1989) diz: "Ninguém ignora tudo. Ninguém sabe tudo. Todos nós sabemos alguma coisa. Todos nós ignoramos alguma coisa". Investigar o que ocorreu e como ocorreram as transformações, servem para fortalecer o papel da educação para percorrer, trançando uma trilha para evolução da qualidade nos processos de ensino e aprendizagem.

Consequentemente, é necessário, encontrar maneiras de alcançar, relacionar e entrelaçar estes conhecimentos de formas práticas, para que não ocorram dificuldades entre o ensinar e o aprender, assim como na abordagem da teoria da complexidade há entendimento de que o todo necessita das partes e estas necessitam do todo.

A infraestrutura física, os espaços disponíveis na escola são elementos que os gestores, professores e coordenadores precisam gerenciar. É preciso ter entendimento das mudanças pedagógicas para o ensino híbrido, e definir como serão realizadas, em que espaços, tempo, quais materiais a escola tem disponível para agregar a essa metodologia. Viabilizar os espaços que poderão ser aproveitados, os momentos para estudos e pesquisas, equipamentos tecnológicos e digitais que serão utilizados.

Logo, o professor por sua vez deverá planejar estratégias que contemplem melhor a combinação escolhida, e o processo ensino e aprendizagem. É preciso, estabelecer no planejamento, para melhor efetividade, atividades: para engajar os estudantes propondo atividades que melhore o nível de interações tanto com professor quanto com os estudantes e com o currículo, ou seja, com o tema a ser desenvolvido, priorizando a autonomia do estudante, aprimorando as lições, escolhendo os melhores e mais acessíveis recursos: tecnológicos e metodológicos e práticas pedagógicas que estimulem os estudantes a aprenderem, assim como utilizar metodologias diversas. É preciso que os professores troquem ideias entre si, das práticas que utilizam, do que está dando certo, buscando aperfeiçoar cada vez mais. Por isso é importante uma rede colaborativa entre professores, 
gestores e coordenadores, ou até mesmo com a participação dos pais e demais atores da educação que possam auxiliar nessa projeção de avanços.

\section{CONCLUSÃO}

A investigação dos modelos de ensino híbrido é um dos caminhos possíveis para a melhoria da educação pública. A educação nunca mais será a mesma após a pandemia do COVID-19. Essa afirmação é dita por inúmeras profissionais da área. É certo que nem as pessoas serão as mesmas. Foram intensas as mudanças ocorridas.

Nesse sentido, este artigo contribuirá para ampliar a temática e faz uma breve explanação do olhar para a escolha do/s modelos para o ensino híbrido, observando a realidade de cada instituição de ensino, apontando a importância dos atores educacionais nessa nova metodologia de ensino, onde todos são importantes e precisam se integrarem para que tenham êxito, assim como é necessário a ressignificação das práticas pedagógicas, a reformulação do planejamento educacional, o diagnóstico assertivo e a parceria não só das pessoas que integram o corpo docente, mais todos inclusive pais e famílias.

É preciso pensar o ensino híbrido como uma das formas de alcançar os estudantes, para tentar preencher as lacunas vazias que ficaram para trás devido a pandemia. Mas, para isso é preciso entender os novos processos, os caminhos trilhados na superação das dificuldades para adequação e/ou adaptação ao ensino remoto. $O$ ensino remoto poderá servir de base se for analisado o que deu certo e o que não deu, assim como o que poderá ser adaptado para o ensino híbrido.

Pois, "ensinar não é apenas uma mera transferência de conhecimentos de uma pessoa mais velha para uma mais nova, é muito mais. (FREIRE, 2008).” É preciso investigar, conhecer, colocar em prática. Para isso, é preciso pesquisa, análise, trocas de experiências e formação com objetivos claros e que alcance as reais necessidades dos professores e equipes pedagógicas, assim como os gestores escolares.

\section{REFERÊNCIAS BIBLIOGRÁFICAS}

BACHIC, Lilian; TANZI NETO, Adolfo; TREVISANI, Fernando de Mello (org). Ensino Híbrido: personalização e Tecnologia na Educação. Porto Alegre: Penso. 2015. 
BARCELOS, Gilmara Teixeira; BATISTA, Silvia Cristina Freitas. Ensino Híbrido: aspectos teóricos e análise de duas experiências pedagógicas com Sala de Aula Invertida. V. I7 № 2, agosto, 2019. RENOTE. DOI: 10.22456/1679-1916.96587

BRITO, G. S. e PURIFICAÇÃO. Educação e novas tecnologias: um repensar. Curitiba: IBPEX.2006.

CHIZZOTTI, Antônio. Pesquisa em Ciências Humanas e Sociais. Cortez Editora. $2^{\underline{a}}$ ed. São Paulo.

SOUSA, RP., MIOTA, FMCSC., and CARVALHO, ABG., orgs. Tecnologias digitais na educação[online]. Campina Grande: EDUEPB, 20Ir. 276 p. ISBN 978-85-7879-124-7. Available from SciELO Books 〈http://books.scielo.org $>$.

FREIRE, Paulo. A importância do ato de ler: em três artigos que se completam. São Paulo: Autores Associados: Cortez, 1989. Educação como prática da liberdade. 22. ed. Rio de Janeiro: Paz e Terra, 1996.

FREIRE, P. Pedagogia da autonomia: saberes necessários à prática educativa. ed. São Paulo: Paz e Terra, 2008.

HORN, Michel B.; STAKER, Hearther. Blended: usando a inovação disruptiva para aprimorar a educação. Porto Alegre: Penso. 2015.

MORIN, Edgar. Os sete saberes necessários à educação do futuro. 3. ed., São Paulo: Cortez, 20or.

Introdução ao pensamento complexo. Porto Alegre: Sulina, 2005.

MORAN, José Manoel. Novas tecnologias e Mediações pedagógicas. Papirus Editora. São Paulo, 2005. $12^{\underline{a}}$ ed. $173 \mathrm{p}$.

NOVAIS, I. de A. M. Ensino híbrido: estado do conhecimento das produções científicas no período de 2006 a 2016.I43f. Dissertação (Mestrado em Educação) - Universidade Estadual de Maringá, Paraná, 2017.

PADERES, Adriana Marques; RODRIGUES, Regina de Brito; GIUSTI, Sonia Regina. Artigos, Teoria da Complexidade: Percursos e Desafios para a Pesquisa em Educação. FUNADESP - Fundação Nacional de Desenvolvimento do Ensino Superior Particular. PERES, Paula; PIMENTA, Pedro. Teorias e práticas de b-learning. Lisboa: Edições Sílabo Ltda., 20II. 